\title{
Partial premixing effects upon Soot Nanostructure
}

\author{
Chung-Hsuan Huang and Randy L. Vander Wal* \\ The John and Willie Leone Family Department of Energy and Mineral Engineering, \& The EMS Energy \\ Institute, Penn State University, University Park, PA 16802, USA
}

\begin{abstract}
Partial premixing within simple gas jet diffusion flames has a very long history reaching back to the Bunsen flame. Yet HRTEM data of soot from such flames appears absent. Using benzene as the primary fuel with partial premixing tested the chemical path for $\mathrm{C} 5$ production - proceeding through partial benzene oxidation yielding the phenoxy radical followed by $\mathrm{CO}$ loss to produce $\mathrm{C} 5$. A strong variation of lamellae curvature with oxygen content in the primary fuel stream was observed - reflecting the increasing C5 production rate. Generality of the nanostructure dependence upon partial premixing and associated change in gas phase chemistry (compared to pure thermal pyrolysis) was demonstrated using an ordinary laboratory Bunsen burner with ethylene as fuel. Absent partial premixing, soot production is well described by the HACA mechanism, yielding benzenoid aromatics and soot nanostructure consisting of flat lamellae, without curvature, dissimilar to observations described here accompanying partial premixing.
\end{abstract}

Keywords: fuel memory effect, HRTEM, soot nanostructure, partial premixing, lamellae curvature, Benzene.

\section{Introduction}

Recent flame studies have shown that soot can possess profound differences in nanostructure depending upon its formation chemistry [1,2] and temperature history [35] with implications for oxidation [3, 6-8]. By measurements and modeling, soot chemistry varies with fuel [9]. Russo et al. [1] recently found soot $\mathrm{H} / \mathrm{C}$ to be highly dependent upon the parent fuel using ethylene versus methane in premixed sooting flames at similar equivalence ratio and temperature conditions. Additionally the aliphatic content was observed related to the growth history and chemical environment. In other highly detailed studies, applying HRTEM, elemental analysis, oxidative thermogravimetric analysis, and UV-Vis spectroscopy, Alfe et al. [3] showed dependence of soot nanostructure upon fuel, and structure-property relationships between soot nanostructure and "bulk" properties. Apicella et al. [4] found that nanostructure evolved toward larger size aromatic systems throughout the soot formation region in premixed benzene and ethylene flames. Moreover the nanostructure order depended upon fuel, as did the soot H/C content. In prior studies Russo et al. [5] also found the H/C ratio dependent upon fuel, using premixed flames of methane, ethylene and benzene.

In engine studies, several different researchers have characterized nanostructure, identified its dependence upon fuel, engine or combustion conditions, and its impact upon 
oxidation. For example, Boehman et al. [10] compared soot nanostructures of particulates produced from different fuels in a commercial direct injection (DI) diesel engine using HRTEM to show the potential impact of biodiesel blending on the low-temperature oxidation. Subsequent studies expanded upon the relationship between nanostructure and reactivity by comparison of biodiesel (Song, Lapuerta) and Fischer-Tropsch diesel fuel [11, 12], impact of EGR [13], and engine load [14], speed and torque [15], Vander Wal first illustrated the impact of nanostructure upon reactivity [16], with illustration of its dependence upon fuel and formation conditions [17], extending this to oxygenated fuels [18] and also its impact upon reactivity [19]. Recently the impact of biodiesel fuel in a diesel engine [20] and of turbulence induced mixing (in a jet engine) upon nanostructure [21] was shown using HRTEM to identify fullerenic nanostructure in the emitted PM.

Why is curvature, i.e. fullerenic nanostructure of interest? As hypothesized it relates to the fuel air stoichiometry, namely the equivalence ratio $\phi$ that is of great practical relevance. In diesel and gas turbine engines fuel atomization and vaporization produce fuel-rich regions that mix with air (concurrent with evaporation) leading to partial premixing. This study sought to test the path towards curvature and show the generality of partial premixing, using simple gas-jet flames to identify the origin of curvature and demonstrate the relevancy of partial premixing to nanostructure in soot.

In this study two flames were investigated to test the relation between $\mathrm{C}_{5}$ chemistry and soot nanostructure. To identify limits, soot from a partially premixed diffusion flame with benzene as fuel was studied for comparative nanostructure. Second, an ordinary Bunsen flame fueled with ethylene $\left(\mathrm{C}_{2}\right)$ tested the generality of the $\mathrm{C}_{5}$ production by partial premixing, with evidence again being production of curvature in soot nanostructure.

\section{Experimental}

Bunsen flames are well known examples of partially premixed flames, typically stabilized on an open tube, as a gas jet. Variable premixing was introduced in a Bunsen flame configuration in order to stabilize the flame. The versatility of such flames is their stoichiometry. The relevancy of Bunsen flames to combustors and engines is that fuel sprays establish a diffusion flame that becomes partially mixed, the degree depending upon location and time [22]. Different fuels were used in this flame configuration with results presented below.

To test the oxidative pyrolysis chemistry leading to C5 formation, a gas jet diffusion flame was used with varied levels of partial premixing using benzene and oxygen. Given the high sooting propensity of benzene; nitrogen dilution was used to manage the soot load and maintain a close-tipped flame. Clearly the varied oxygen levels will inherently change the adiabatic flame temperature, but by nitrogen substitution, the same flame temperature may be maintained while keeping fuel concentration roughly constant [23].

Note that partial premixing is a term best applied for lower levels of oxygen, such as in diffusion flames with $\Phi>3$; levels for which burner stabilized premixed flames are not operable. Streamlines in a buoyantly driven diffusion flame are convergent and nonmonotonic in temperature and mixture fraction, with the exception of the center streamline. Guided by precedence of previous studies illustrating the sequence of soot 
inception and growth along this path, sampling of so-termed mature soot was from this central axis with sampling approximately $5 \mathrm{~mm}$ below the visible flame tip.

\section{Partially premixed diffusion flame}

To investigate the effect of fuel/air partial premixing ratio on soot nanostructure, a coflow burner with a central fuel jet (I.D $=11.1 \mathrm{~mm}$ ) surrounded by a co-flowing air stream (I.D=101.6 mm) burner designed by Santoro et al. (1983) was applied to produce the diffusion flame for soot particle formation and collection. In this study, the total flow rate of the central fuel jet was set at $300 \mathrm{sccm}$ as the combination of methane base flame (to maintain main flame stability), dosed fuel and added oxygen. The co-flow was set at 43 slm air to stabilize the center diffusion flame. Benzene was fed by using argon as the carrier gas through a bubbler at ambient $\left(20^{\circ} \mathrm{C}\right)$ temperature. The methane $\left(\mathrm{CH}_{4}\right)$ and argon (dilution) mixture ratio was $1: 1$ to create non-sooting diffusion base flame (light blue flame). Oxygen at 0,10 and $20 \%(\mathrm{v} / \mathrm{v})$ was added to the argon-fuel stream while maintaining the total flow rate at $300 \mathrm{sccm}$, thereby maintaining similarity of flame height. The tested fuel/air equivalence ratios are summarized in Table 1. Temperatures were not measured in the sooting region of these flames, but adiabatic estimates of peak flame temperature for these three cases were within $200 \mathrm{~K}$ of each other [24]. True values are considerably less, due to strong flame (soot) radiation $[25,26]$.

Soot particles were directly collected within the close-tip diffusion flame by a thermophoretic sampling device with 300 mesh lacy carbon grid for further soot nanostructure HRTEM analysis. Thermophoretic sampling methodology has been well described and has a several-decade history. Briefly, the device was driven by a $\mathrm{N}_{2}$ cylinder, and to ensure one cycle sampling period can be done within 50 $\mu \mathrm{s}, 25-30$ PSI gas pressure was applied to the device, with further details and demonstrations presented elsewhere [27, 28]. To avoid further oxidize collected-soot, only one sampling cycle was applied to sample collection. The soot samples were collected at the central axis of the flame at the location of peak soot. The spatial resolution is defined by the central 2-mm portion of the TEM grid, where variations in aggregate structure or primary particle size were not visibly evident during examination. The overall schematic of the flame system is shown in Fig. 1.

Table 5.1: Tested fuels and the corresponding fuel/air equivalence ratios.

\begin{tabular}{|l|l|l|l|}
\hline Fuels & Pure & $10 \% \mathrm{O}_{2}$ & $20 \% \mathrm{O}_{2}$ \\
\hline $\mathrm{C}_{6} \mathrm{H}_{6}$ & $\phi=\infty$ & $\phi=5.2$ & $\phi=10.4$ \\
\hline
\end{tabular}

\section{Bunsen flame}

To further investigate the fuel/air ratio effect on soot nanostructure evolution, a commercial Bunsen burner (with fuel jet inner diameter $10 \mathrm{~mm}$, with length $120 \mathrm{~mm}$ tube) burning gas fuel ethylene $\left(\mathrm{C}_{2} \mathrm{H}_{4}\right)$ was also used in this study. The air nozzle on the Bunsen burner was used to vary the air inlet flow rate by adjusting the nozzle to be completely closed for limited air inlet and completely opened when ambient air is required. In general the fuel-to-air ratio for a standard laboratory Bunsen burner is 2:1 when the air nozzle is completely opened. Hence the fuel/air equivalence ratio $(\Phi)$ can be estimated as $\sim 7.2$. In this study, a $100 \mathrm{sccm}$ flow rate of $\mathrm{C}_{2} \mathrm{H}_{4}$ produced a close-tip 
diffusion flame. The derived soot particles were directly collected within the diffusion flame by same thermophoretic sampling device and operation procedure addressed above for following soot nanostructure study.

\section{Soot physical structure characterization - HRTEM}

Initial TEM images were taken using a JEOL 2010F, high resolution TEM (HRTEM). The instrument was operated at $200 \mathrm{keV}$ using a field emission source. To ensure that the selected region of interest (ROI) is representative, generally more than 4-6 regions, widely separated, were examined on each grid primarily and secondarily to ensure even coverage, which is taken as an indicator of flow uniformity and sampling by deposition. To reduce and to avoid the human bias on choosing ROIs and images, the operation procedures were followed an established and proven standard operation procedure (SOP), as documented in prior work [21]. Digital images were acquired by the SOP and subsequently processed using custom algorithms (fringe analysis) written with MATLAB software [29]. Two nanostructure parameters, carbon lamella length and tortuosity/curvature (equivalent to positive (inward) curvature as all lamella are oriented similarly), based on processed TEM images were subsequently extracted by fringe analysis. The results of the processed images were exported to the program Kaleida Graph for subsequent data analysis. The means' of fringe (carbon lamella) length and curvature distribution that are reported here were extracted from two-parameter lognormal probability density function curve fitting, addressed in the equation (1), below, as,

$$
f(x)=\frac{1}{x \sigma_{y} \sqrt{2 \pi}} \exp \left[-\frac{1}{2 \sigma_{y}^{2}}\left(\ln x-\mu_{y}\right)^{2}\right]
$$

where $\sigma_{y}$ is the geometric standard deviation and $\mu_{y}$ is the mean of $\ln (\mathrm{x})$. Further details of the TEM image selection operation procedure and the image processes are reported elsewhere [29-32].

A key advantage of HRTEM is direct visualization allowing for selection of analyzed regions, compared to X-ray or Raman spectroscopy. More importantly, X-ray diffraction theory breaks down for lamellae with lengths of order few nanometers or less while lamellae curvature is unaccounted for by Bragg diffraction theory. Additionally there is no theory underpinning the extraction of fullerenic nanostructure from either Raman or $\mathrm{X}$-ray spectra. Therein it would be unclear what physical value these measurements would provide or how to compare them to the observed lamella length and curvature via HRTEM.

\section{Results and Discussion}

\subsection{Benzene PPF (partially premixed flame)}

The diffusion flame presents a complicated chemistry wherein a parcel of fuel undergoes a slow rise in temperature from cold-gas to flame temperature over the course of a few hundred milliseconds in a typical gas-jet, laboratory scale flame. Continued pyrolysis occurs in the course to soot formation. Detailed gas sampling and analysis studies have shown this chemical progression [33-35].

To directly test the partial premixing for C5 production and curvature, benzene was 
chosen as the first test fuel. Partial oxidation ought to lead to ample C5 via reaction (1) [36] with the alternate path being recombination of the resonance stabilized radicals, (reaction 2) [37]. This combination ought to lead to fullerenic structures in soot reflecting C5 species. Indeed, Fig. 2 (A) shows poorly ordered soot for pure benzene but increasing fullerenic structure shown in Fig. 2 (B) and (C) with partial premixing. Lamellae with small radii of curvature are shown, many as concentric pairs or nested, multiple lamella segments. The image analysis shows this trend with partial premixing more clearly by illustrating the marked decrease in length with corresponding increase in curvature as summarized in Fig. 3. The differences in curvature with various oxygen contents are shown in Fig. 4, for benzene (A) as fuel.

As is well documented, soot production is non-monotonic with oxygen addition, initially increasing for the reason of increasing intermediates and opening new pathways towards soot, via odd-numbered carbon species [35,36] (while larger $\mathrm{O}_{2}$ addition leads to soot reduction by oxidizing soot and its precursors). These new paths are not encompassed by the C2-based HACA mechanism [37].

$$
\begin{gathered}
\mathrm{C}_{6} \mathrm{H}_{6}+\mathrm{O}_{2} \rightarrow \mathrm{C}_{6} \mathrm{H}_{5} \mathrm{OH} \rightarrow \mathrm{C}_{6} \mathrm{H}_{5} \mathrm{O}+\mathrm{H}^{\cdot} \rightarrow \mathrm{cC}_{5} \mathrm{H}_{5}+\mathrm{CO} \\
\mathrm{C}_{3} \mathrm{H}_{3}+\mathrm{C}_{2} \mathrm{H}_{2} \rightarrow c C_{5} \mathrm{H}_{5}
\end{gathered}
$$

Partial oxidation introduces odd numbered carbon species along with cyclopentadiene. In principle thermal pyrolysis can produce odd numbered carbon species such as allyl and propargyl radicals under flame conditions but the conjecture here, supported by in other situ sampling measurements [36, 38, 39] is that such species concentrations will be too low to obtain significant cyclopentadiene concentrations yielding substantial nanostructure curvature. Yet another route towards C5 structures is via PAH combinative growth wherein skeletal rearrangements can lead to five membered rings. However relative to partial benzene oxidation or propargyl plus acetylene addition paths, this route is deemed likely insignificant given the lower PAH concentrations compared to benzene and C3 plus the slower kinetic rates for these stereo-specific reactions and concerted skeletal rearrangements. Such ring addition processes might be expected to proceed more readily on the soot surface given the $\pi$ - $\pi$ stabilization coupled with maintaining reactive edge sites accessible by a PAH orientation parallel to the soot surface. Instead, partial oxidation of benzene, a dominant hydrocarbon in soot forming flames is expected to yield cyclopentadiene concentrations sufficient to realize visible curvature in soot nanostructure. The experiments here were designed to test this chemical path with the observable being the curvature in the soot lamella. Image analysis provided a quantitative basis for comparisons.

Linking $\mathrm{C}_{5}$ and particle structure is lamella curvature - the observable when $\mathrm{C}_{5}$ is incorporated. HRTEM analysis of soot from low-pressure, benzene/argon/oxygen flames by Hebgen et al. [40] revealed high curvature in lamella throughout, suggestive of, but not conclusive for, $\mathrm{C}_{5}$ as origin. Both mechanisms and measurements have firmly identified $\mathrm{C}_{5}$ and $\mathrm{C}_{5}$ containing aromatics in the path to fullerene formation [41, 42]. By TEM and Soxhlet extraction, fullerenes were found to add to or be trapped within the 
"fullerenic" soot matrix [43]. Indicative of the importance of $\mathrm{C}_{5}$ and its origin through the phenoxy radical, the fullerene yield (and lamella curvature) in these flames was strongly dependent upon fuel/air equivalence ratio, $\Phi$. This study reciprocally maps the curvature of soot nanostructure upon $\Phi$.

Whether $\mathrm{C}_{5}$ (and related $\mathrm{PAH}$ ) formation occurs via gas-phase reactions or via surface mediated processes, $\mathrm{C}_{5}$ production (and integration) dominates lamellae curvature. Facile, known gas-phase routes to $\mathrm{C}_{5}$, and varied studies showing its relevance to partially premixed systems are the basis for interpreting the fullerenic nanostructure in terms of these pathways with direct addition. Still, these observations do not exclude 5membered ring formation on the soot surface from gas-phase supplied precursors.

Of particular note is that images did not show liquid-like particles nor black carbon seeds within translucent oil-like droplets or other amorphous material, as has been seen and reported elsewhere in soot studies using vaporized liquid fuels in gas jet flames [28, 44]. This is attributed to the lower fuel concentration, limited by vapor pressure in this study, rather than using atomized fuel. Therein curvature formation is not attributed to carbonization or graphitization processes associated with condensed phase organic. Moreover oxidation was not found by noting absence of fragmented surface lamellae or reduced primary particle sizes. Notably the added $\mathrm{O}_{2}$ amounts are far from perturbative; the adiabatic flame temperature does exceed $1900 \mathrm{~K}$ for the highest $\mathrm{O}_{2}$ addition while being slightly lower for the other flames [34]. Notably the peak temperature along the center streamline is at the flame sheet lying well within the soot oxidation region, considerably downstream of the maximum soot volume fraction $\left(f_{v}\right)$ region and sampling position [38].

\subsection{Angle tilting of TEM curved shells Section}

To assist in distinguishing the fullerenic nanostructure angle tilting images were obtained. If curved hexagonal sheets are observed along the axis of curvature, these too will appear as fullerenic nanostructure. However as the viewing/imaging axis tilts relative to the axis about which the lamella is curved, an increasingly elongated ellipse will be imaged within the TEM focal plane. Such curvature is restricted to $2 \mathrm{D}$, while true fullerenic curvature would be $3 \mathrm{D}$, enabled by the presence of 5 -membered rings. For a true spherical structure, there is not an axis of curvature but only a point. Regardless of the angle of tilt (in any direction) between the image plane containing this point and the viewing axis, the imaged lamellae will still show the same curvature, without distortion. An alternative mental construct would be to imagine the variation in cross section in slicing a tube versus a sphere at varied inclinations.

Figure 5 shows a sequence of TEM images, collected at a series of angle tilts, from $25^{\circ}$ to $+25^{\circ}$, with respect to center, defined as zero. As illustrated for the lamellae marked by the arrows shown, and overall, the curved lamellae shape and orientation (equivalent radius of curvature) do not appear to significantly change between the two opposing viewing directions. These profiles support interpretation of curved lamellae in these 2-D projections as fullerenic, 3-D shells and fragments with such structure contingent upon incorporated C5 species. 


\subsection{Bunsen Flame}

To further compare the effect of partial premixing on curvature formation, a simple Bunsen burner was applied to test for a well-studied fuel, ethylene. Without base fuel, coflow or inert dilution, this flame presents a very simple system by which to test the generality of partial premixing upon nanostructure. As Fig. 6 shows, the absence of partial premixing yielded primary particles with recognizable lamella concentrically oriented around the particle perimeter. Introduction of air, by opening the mixing slot creates a nominal $\Phi$ of $\sim 7.2$. The resulting nanostructure evolution is markedly different, now with many highly curved lamellae, in individual, paired or group assemblies as shown in Fig. 6. By fringe analysis, upon partial premixing, tortuosity as measure of curvature increases by $\sim 10 \%$, with the median of the log-normal fitted distribution exhibiting a similar shift, indicating more curvature in the lamellae. For this pure fuel, soot formation proceeds via the nominal acetylene production, $\mathrm{C} 6$ formation and PAH growth sequence [45-50]. With oxygen inclusion, odd numbered carbon (C3) species, and C5 production proceeds.

\subsection{Reference Images}

As illustration of fullerenic nanostructure in soots from engines and combustors, Fig. 7 shows HRTEM images of soots collected from a Mercedes 4.61 (passenger vehicle) burning a 10:90 fuel blend of B100 and ULSD (designated as B10) and a CFM-56-2C GE jet engine running on JP-8. The arrows mark the clearest lamellae with high curvature. Each of these images can be contrasted with the layered nanostructure evident in the preceding image of soot from a diffusion flame.

\section{Conclusions}

Partial premixing is a combustion condition both prevalent and relevant to soot formation in practical systems with liquid fuel sprays such as in engines and combustors. The kinetics for C5 production by partial oxidation of soot precursors is established. As known by fullerene science, C5 incorporation into lamella leads to their curvature. The new observation is that the soot nanostructure under conditions of partial premixing (yet still soot producing) reflects C5 production. Therein soot nanostructure depends upon $\phi$, a previously unconsidered aspect in soot formation. Moreover, curvature is uniquely dependent upon C5, unlike other measures of nanostructure such as lamella length or separation distance. This dependence then raises the possibility that the curvature may be related to the local combustion environment, i.e. equivalence ratio in which the soot formed.

\section{Acknowledgments}

The author gratefully acknowledges support for this work was through NSF CBET1342920 with the Pennsylvania State University, University Park, PA 16802.

\section{References}

[1] C. Russo, A. Tregrossi, A. Ciajolo, Proc. Combust. Inst. 35 (2015) 1803-1809. 
[2] H. Nakamura, S. Suzuki, T. Tezuka, S. Hasegawa, K. Maruta, Proc. Combust. Inst. 35 (2014) 3397-3404.

[3] M. Alfè, B. Apicella, R. Barbella, J.N. Rouzaud, A. Tregrossi, A. Ciajolo, Proc.

Combust. Inst. 32 Vol. I (2009) 697-704.

[4] B. Apicella, P. Pré, M. Alfè, a. Ciajolo, V. Gargiulo, C. Russo, A. Tregrossi, D.

Deldique, J.N. Rouzaud, Proc. Combust. Inst. 35 (2015) 1895-1902.

[5] C. Russo, M. Alfe, J.N. Rouzaud, F. Stanzione, A. Tregrossi, A. Ciajolo, Proc.

Combust. Inst. 34 (2013) 1885-1892.

[6] J. Camacho, Y. Tao, H. Wang, Proc. Combust. Inst. 35 (2014) 1887-1894.

[7] L. Wang, C. Song, J. Song, G. Lv, H. Pang, W. Zhang, Proc. Combust. Inst. 34 (2013) 3099-3106.

[8] J. Song, C. Song, Y. Tao, G. Lv, S. Dong, Combust. Flame. 158 (2011) 446-451.

[9] M. Sirignano, M. Alf, A. Tregrossi, A. Ciajolo, A. D’Anna, Proc. Combust. Inst. 33 (2011) 633-640.

[10] A.L. Boehman, J. Song, M. Alam, Energy Fuels 19 (2005) 1857-1864.

[11] J. Song, M. Alam, A.L. Boehman, U. Kim, Combust. Flame. 146 (2006) 589-604.

[12] M. Lapuerta, F. Oliva, J.R. Agudelo, A.L. Boehman, Combust. Flame 159 (2012) 844-853.

[13] K. Al-Qurashi, A.D. Lueking, A.L. Boehman, Combust. Flame 158 (2011) 16961704.

[14] H.J. Seong, A.L. Boehman, Energy Fuels 25 (2011) 602-616.

[15] K. Yehliu, O. Armas, R.L. Vander Wal, A.L. Boehman, Combust. Flame 160 (2013) 682-691.

[16] R.L. Vander Wal, A.J. Tomasek, Combust. Flame 134 (2003) 1-9.

[17] R.L. Vander Wal, A.J. Tomasek, Combust. Flame 136 (2004) 129-140.

[18] R.L. Vander Wal, C.J. Mueller, Energy Fuels 20 (2006) 2364-2369.

[19] R.L. Vander Wal, A. Yezerets, N.W. Currier, D.H. Kim, C.M. Wang, Carbon 45 (2007) 70-77.

[20] R.L. Vander Wal, A. Strzelec, T.J. Toops, C. Stuart Daw, C.L. Genzale, Fuel 113 (2013) 522-526.

[21] C.H. Huang, R.L. Vander Wal, Energy Fuel 27 (2013) 4946-4958.

[22] Y-C. Chen, N. Peters, G.A. Schneemann, N. Wruck, U. Renz, M.S. Mansour, Combust. Flame 107 (1996) 223-244.

[23] D. Razus, M. Molnarne, O. Fuß, Chem. Eng. Proc. 43 (2004) 775-784.

[24] Y. Wang, Effects of Fuel Molecular Structures on Pollutants in Co-flow Laminar Flames, Ph.D. Thesis, Department of Mechanical and Nuclear Engineer, The Pennsylvania State University, University Park, PA, 2015. 
[25] A. Fuentes, R. Henríquez, F. Nmira, F. Liu, J.L. Consalvi, Combust. Flame 160 (2013) 786-795.

[26] F. Liu, K.A. Thomson, G.J. Smallwood, Combust. Flame 160 (2013) 1693-1705.

[27] R.A. Dobbins, C.M. Megaridis, Langmuir 3 (1987) 254-259.

[28] M. Kholghy, M. Saffaripour, C. Yip, M.J. Thomson. Combust. Flame 160 (2013)

2119-2130.

[29] K. Yehliu, R.L. Vander Wal, A.L. Boehman, Combust. Flame 158 (2011) 1837-1851

[30] R.L. Vander Wal, A.J. Tomasek, K. Street, D.R. Hull, W.K. Thompson Appl. Spectrosc. 58 (2004) 230-237.

[31] R.L. Vander Wal, A.J. Tomasek, M.I. Pamphlet, C.D. Taylor, W.K. Thompson, J. Nanopart. Res. 6 (2004) 555-568.

[32] C.K. Gaddam, R.L. Vander Wal, Combust. Flame 160 (2013) 2517-2528.

[33] T.R. Melton, F. Inal, S.M. Senkan, Combust. Flame 121 (2000) 671-678.

[34] B.A.V. Bennett, C.S. McEnally, L.D. Pfefferle, M.D. Smooke, and M.B. Colket. Combust. Flame 127 (2001) 2004-2022.

[35] M.J. Castaldi, N.M. Marinov., C.F. Melius, J. Huang, S.M. Senkan, W.J. Pitz, C.K. Westbrook, Twenty-Sixth Symposium on Combustion/The Combustion Institute (1996) 693-702.

[36] C.S. McEnally, L.D. Pfefferle, B. Atakan, K. Kohse-Hoinghaus, Prog. Energy Combust. Sci. 32 (2006) 247-294.

[37] M. Frenklach, Phys. Chem. Chem. Phys. 4 (2002) 2024-2037.

[38] C.S. McEnally, L.D. Pfefferle, Combust. Flame 121 (2000) 575-592.

[39] H. Richter, S. Granata, W.H. Green, J.B. Howard, Proc. Combust. Inst. 30 (2004)1397-1405

[40] P. Hebgen, A. Goel, J.B. Howard, L.C. Rainey, J.B. Vander Sande, P. Combust. Inst. 28 (2000) 1397-1404.

[41] W.J. Grieco, J.B. Howard, L.C. Rainey, J.B. Vander Sande, Carbon 38 (2000) 597614.

[42] H.A. Richter, T.G. Benish, O.A. Mazyar, W.H. Green, J.B. Howard, P. Combust. Inst. 28 (2000) 2609-2618.

[43] A. Goel, P. Hebgen, J.B. Vander Sande, J.B. Howard, Carbon 40 (2002) 177-182.

[44] M. Saffaripour, A. Veshkini, M. Kholghy, M.J. Thomson, Combust. Flame 161 (2014) 848-863.

[45] H. Richter, J.B. Howard, Prog.Energy Combus. Sci. 26 (2000) 565-608.

[46] H. Wang, M. Frenklach, Combust. Flame 110 (1997) 173-221.

[47] M. Frenklach, J. Warnatz, Combust. Sci. Techno. 51 (1987) 265-283. 
[48] T.G. Benish, A.L. Lafleur, K. Taghizadeh, J.B. Howard, Proc. Combust. Inst. 26 (1996) 2119-2326.

[49] S. Macadam, J.M. Beer, A.B. Hoffmann, Proc. Combust. Inst. 26 (1996) 2295-2302.

[50] A. Kazakov, M. Frenklach, Combust. Flame 112 (1998) 270-274. 


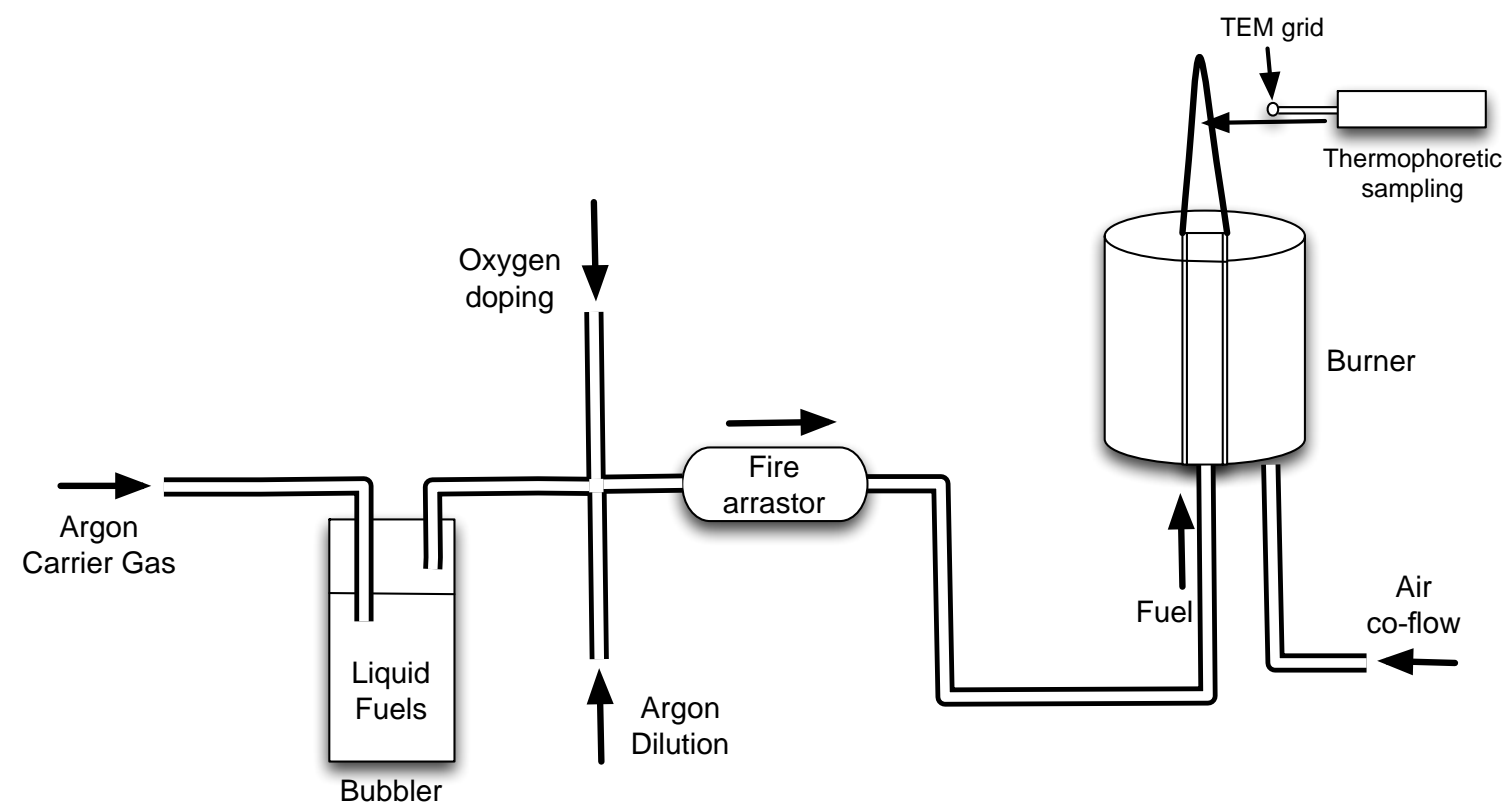

Figure 1 . The schematic of partially premixed discussion flame system with Santoro-style burner.

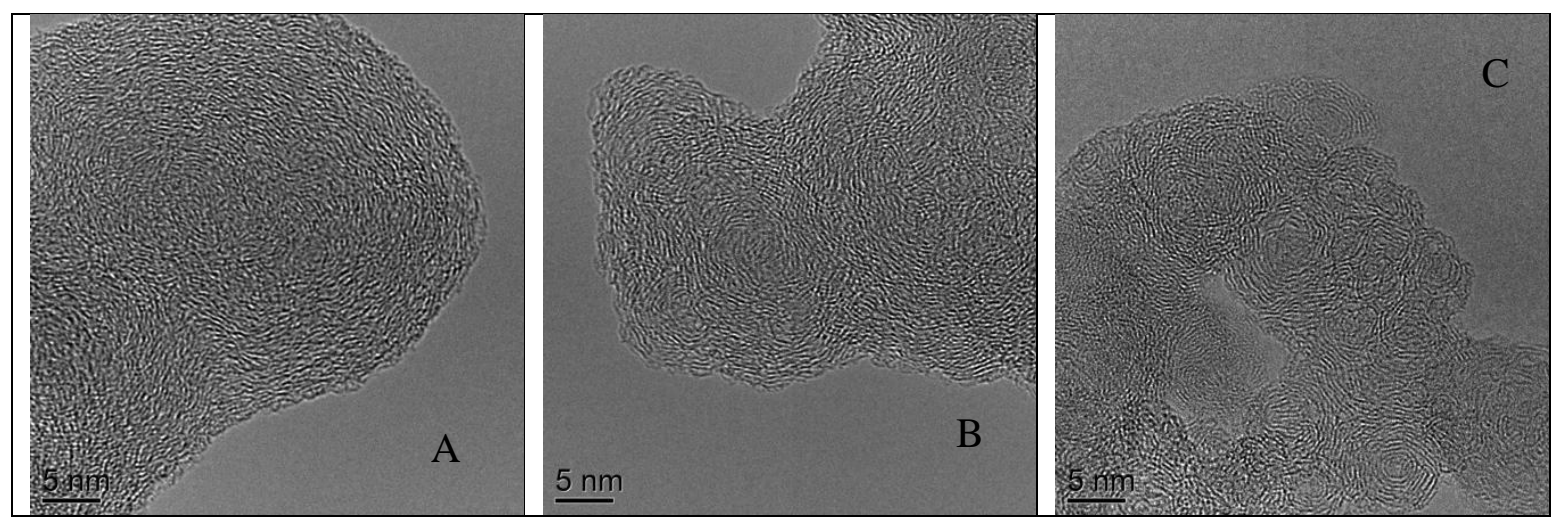

Figure 2. Soot aggregate morphology and nanostructure derived from Benzene fuel with $0,10, \& 20 \% \mathrm{O}_{2}$ doping, respectively.

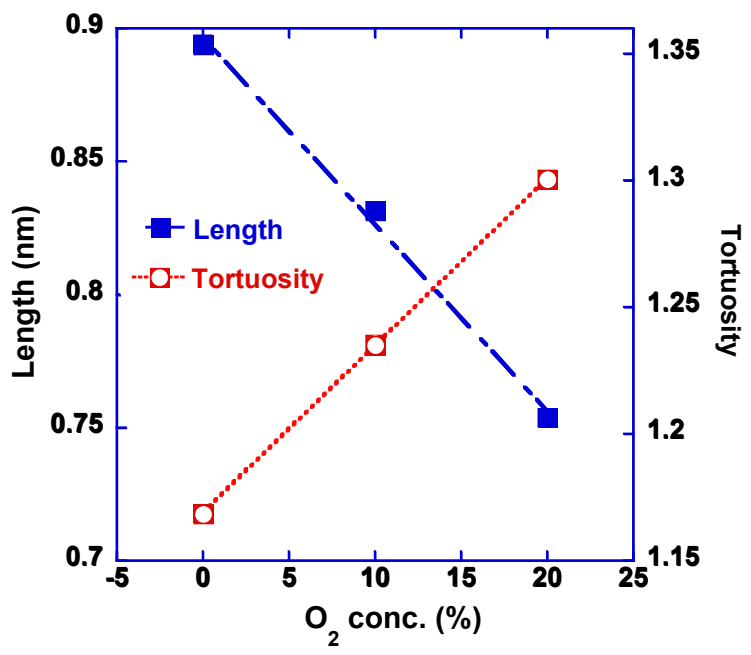

Figure 3. Fringe analysis summary of length $\&$ tortuosity distribution from Benzene with $0,10, \& 20 \% \mathrm{O}_{2}$ doping. 


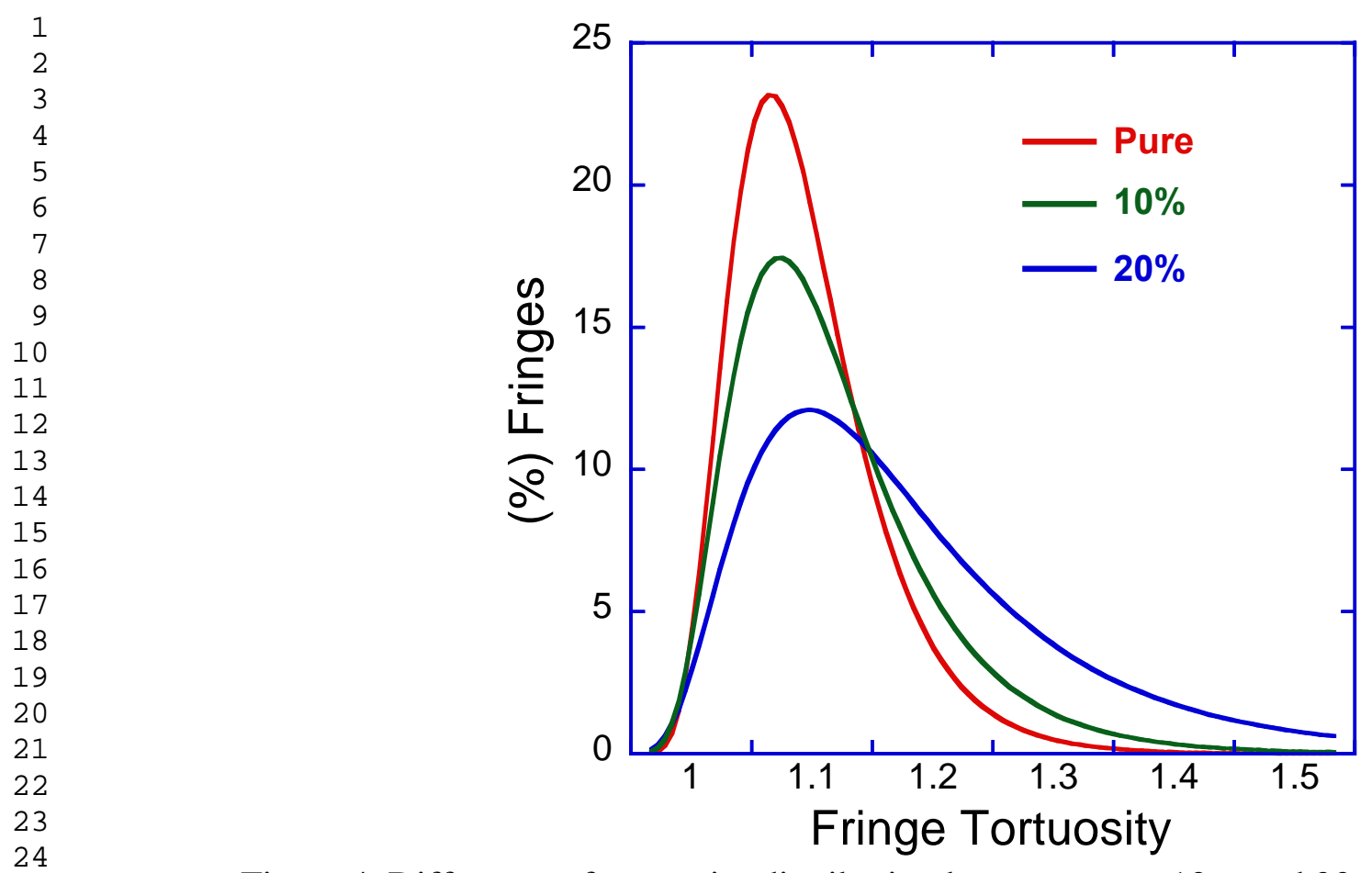

Figure 4. Difference of tortuosity distribution between pure, $10 \%$ and 20\% Oxygen doping from Benzene.

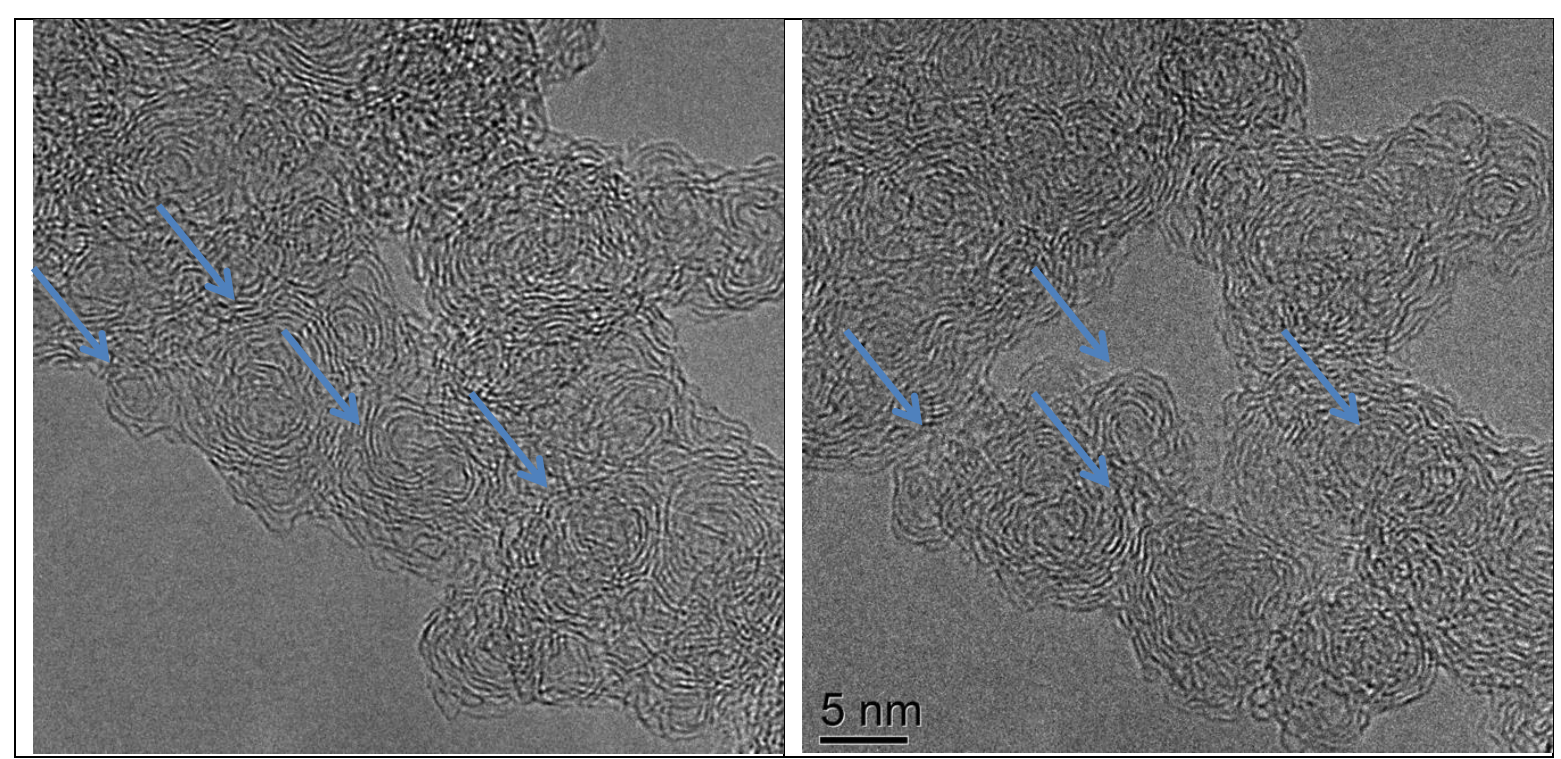

Figure 5. Representative angle tilt from $-25^{\circ}$ (left) to $+25^{\circ}$ (right) HRTEM images of soot nanostructure derived from Benzene flame with $20 \%$ oxygen doping. 


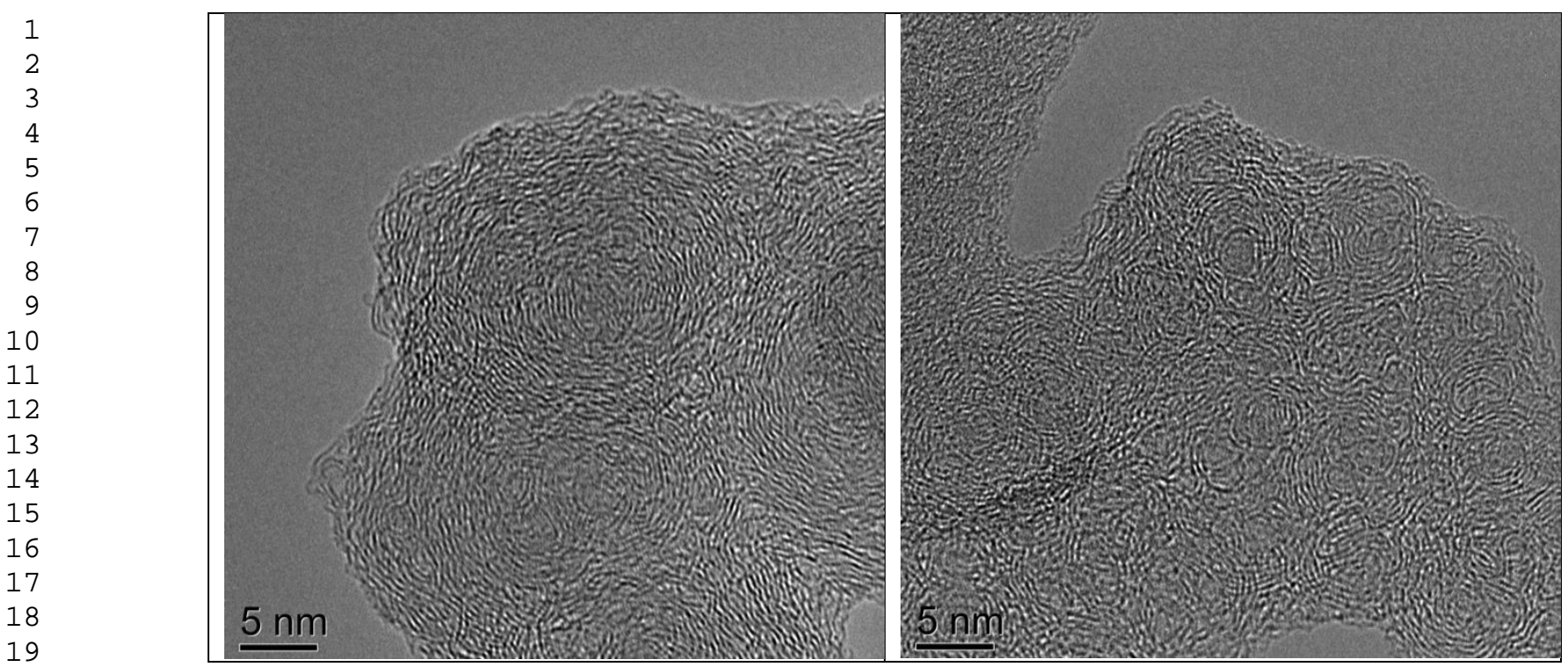

Figure 6. Soot nanostructure derived from Bunsen burner test with $\mathrm{C}_{2} \mathrm{H}_{4}$ fuel (left with nozzle closed, right with nozzle open)
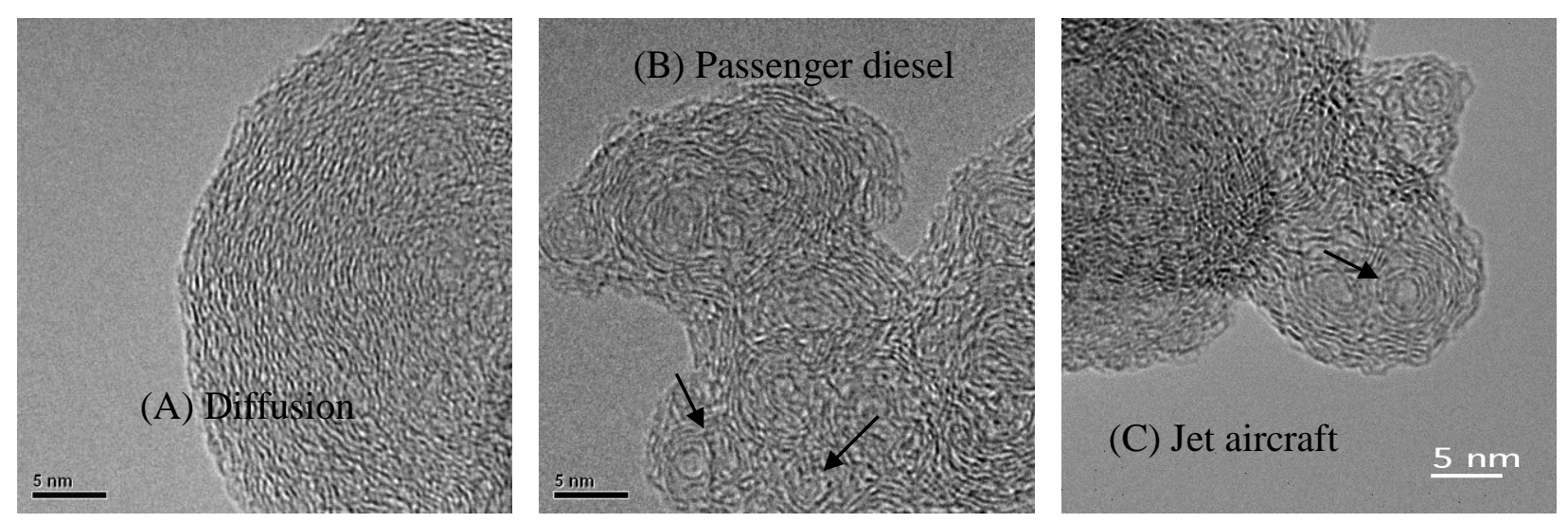

Figure 7. HRTEM images of soot sampled from (A) a laminar gas-jet diffusion flame of ethylene, (B) a Mercedes 4.61 (passenger vehicle) burning a 10:90 fuel blend of B100 and ULSD and (C) a CFM-56-2C GE jet engine running on JP-8. Source: Author's work. 